rev.relac.int.estrateg.segur.12(1):103-130,2017

\title{
NARCOTRÁFICO Y EL DESAFÍO A LA SEGURIDAD EN LA TRIPLE FRONTERA ANDINA*
}

\author{
Valeska Troncoso Zúñiga**
}

\section{Resumen}

El narcotráfico es la principal manifestación del crimen organizado en la Triple frontera andina. La permeabilidad de esta frontera y las limitaciones a su control efectivo han posibilitado la instalación de vías fluviales y terrestres convirtiéndose en las principales rutas para el transporte de drogas desde Bolivia y Perú hacia Chile, lo que supone una revalorización estratégica de esta zona fronteriza históricamente

El presente artículo de reflexión es producto de los avances de investigación de la tesis doctoral titulada "El Crimen Organizado Trasnacional y el desafío de la seguridad en la Triple Frontera de Bolivia, Chile y Perú, desde la perspectiva de los actores estatales (2006-2015)" del Doctorado en Ciencias Sociales, de la Universidad de Buenos Aires ( UBA).

** Doctoranda en Ciencias Sociales, Universidad de Buenos Aires. Magíster en Estudios Internacionales, Universidad de Santiago de Chile. Licenciada en Historia, Universidad del Desarrollo. Graduada de los cursos "Coordinación Interagencial y Contraterrorismo" y "Combating Transnational Organized Crime and Illicit Networks in the Americas" en William Perry Center for Hemispheric Defense Studies (CHDS). Coeditora del libro "Desafíos del sector defensa. Gobernabilidad y Seguridad en América Latina" (2013). Coautora en el libro "Arquitectura de la violencia en Latinoamérica" (2015) y Coautora en los artículos "La Violencia Vinculada a la Criminalidad en Brasil y el Papel de las Fuerzas Armadas en la Búsqueda de la Seguridad Pública" (2015) y "Política internacional y política doméstica en Gabriel González Videla. La sombra de la Guerra Fría" (2016). Académica de la Universidad Santo Tomás, Santiago de Chile. Correo electrónico: valeskatroncoso@santotomas.cl 
considerada bajo el paradigma clásico de la seguridad, debido principalmente a la persistencia de disputas territoriales de origen decimonónico. Desde un abordaje cualitativo el presente artículo analiza el narcotráfico como amenaza a la seguridad en esta triple frontera, siguiendo este derrotero. Primero, describe las particularidades del área en estudio con el propósito de situar el problema. Segundo, aborda los contenidos de la agenda de seguridad internacional, enfatizando la idea que en la Triple frontera andina se superpone una agenda tradicional con una nueva agenda, en donde las llamadas nuevas amenazas cobran relevancia, como es el caso del narcotráfico. $Y$ en tercer término, se analiza la situación del narcotráfico, como amenaza a la seguridad, en sus particularidades nacionales y subnacionales.

Palabras clave: Agenda de Seguridad; Narcotráfico; Nuevas Amenazas; Triple frontera andina

\title{
DRUG TRAFFICKING AND THE CHALLENGE TO SECURITY IN THE TRIPLE ANDEAN BORDERLINE
}

\begin{abstract}
Drug trafficking is the main manifestation of organized crime in the Triple Andean Borderline. The vulnerability of such borderline and the limitations for exerting an effective control over it have allowed the creation of river and terrestrial corridors that have in turn become the principal routes for the transportation of drugs from Bolivia and Peru to Chile. This supposes a strategic reassessment of this borderline zone historically considered in the classical paradigm of security; this is mainly due to the persistence of territorial disputes since the 1800's. From a qualitative approach, this article analyzes drug trafficking as a threat to the security in this triple borderline in three steps: firstly, describing the particularities of the study area to locate the problem. Secondly, discussing the contents of the international security agenda, highlighting the idea according to which in the Triple Andean Borderline there is an overlapping of a traditional agenda with a new one, where the so-called new threats, as drug trafficking, become more relevant. And, thirdly, analyzing the situation of drug trafficking itself as a threat to security, both nationally and sub-nationally.
\end{abstract}

Keywords: Security Agenda; Drug Trafficking; New Threats; Triple Andean Borderline. 


\section{TRÁFICO DE DROGA E O DESAFIO A LA SEGURANÇA NA FRONTEIRA TRIPLE ANDINA}

\section{Resumo}

O tráfico de droga é a principal manifestação do crime organizado na fronteira triple andina. O uso desta fronteira e as limitações ao seu controle efetivo vem possibilitando a instalação de vias fluviais e terrestres que estão se convertendo nas principais rotas para o transporte de drogas desde a Bolívia, Peru até o Chile, o que supõem uma revalorização estratégica desta zona fronteira historicamente considerada baixo o paradigma clássico da segurança, devido principalmente a persistência de disputas territoriais de origem décimo nono. Desde uma abordagem qualitativo o presente artigo analisa o tráfico de droga como uma ameaça a segurança nesta fronteira tripla, continuando com este derrotero. Primeiro, descreve as particularidades da área em estudo com o propósito de localizar o problema. Segundo, aborda os conteúdos da agenda de segurança internacional, enfatizando a ideia que na fronteira andina tripla se sobrepõem uma agenda tradicional com uma nova agenda onde as chamadas novas ameaças cobram relevância, como é o caso do tráfico de droga. E no terceiro termo, analisasse a situação do tráfico de droga, como ameaça a segurança em suas particularidades nacionais e subnacionais.

Palavras chave: Agenda de Segurança; Tráfico de droga; Novas Ameaças; Fronteira andina tripla

\section{Introducción}

En América Latina, el tráfico de drogas es la principal manifestación de la criminalidad organizada. En esta región se produce el $100 \%$ de la cocaína que se consume a nivel mundial y es a partir del tráfico de drogas que se potencian directa o indirectamente el comercio ilegal de armas pequeñas y livianas, la industria del secuestro, el contrabando, la corrupción y otros ilícitos (Bartolomé, 2009) .
Estas amenazas se diferencian de las tradicionales puesto que poseen una naturaleza no militar y su alcance es transnacional, lo que sugiere nuevos retos para los Estados por el uso de tácticas para traspasar fronteras estatales, las que se contraponen a las formas tradicionales de librar las guerras y a las políticas de seguridad nacional, lo que significa un giro en la forma en la que se concibe la seguridad internacional. 
En el caso específico del área geográfica en donde convergen las fronteras de Bolivia, Chile y Perú, tradicionalmente denominada Triple frontera andina, el desafío está vinculado al problema de la permeabilidad de dicha frontera y las limitaciones a su control efectivo, posibilitado entre otras cosas por sus particularidades geográficas, con baja altura y pocos accidentes geográficos. Por tanto, la vulnerabilidad que presenta esta frontera ya no sólo está vinculada a la persistencia de disputas territoriales de origen decimonónico, sino que también por las amenazas no convencionales tales como la migración ilegal, el contrabando y el narcotráfico.

En efecto, en materia de narcotráfico Bolivia y Perú se encuentran entre los tres principales productores de cocaína a nivel mundial, junto a Colombia, lo que supone un enorme desafío a sus capacidades estatales por la porosidad de sus fronteras y la debilidad de las instituciones estatales. Los efectos del narcotráfico no sólo se perciben en los países en cuestión, sino que también con los cuales comparten amplias extensiones de frontera. En esta línea, Chile se ha convertido en un lugar de trasbordo para grandes cargamentos de cocaína que cruzan la frontera directamente desde los países en estudio, en dirección a $\mathrm{EE}$ $\mathrm{UU}$, lo cual ha generado una creciente preocupación ante la posibilidad de que el incremento de las redes de narcotráfico lleven a un aumento en la criminalidad y la violencia urbana.
En este artículo el abordaje de la problemática surge como necesidad de establecer un análisis descriptivo y explicativo de la situación del narcotráfico en la Triple frontera andina. Para ello se toman algunos elementos de la teoría Constructivista de la Relaciones Internacionales desarrollada por Barry Buzan, Ole Waever y Jaap de Wilde para tratar el tema de la construcción de la agenda de seguridad en la Triple frontera andina, configurándose como un marco conceptual que permite un análisis con un enfoque que considera que dicha agenda es dinámica, sujeta a cambios y a una permanente construcción. Además, se complementará con los conceptos de espacios vacíos y fenómenos intermésticos que contribuyen a analizar cuestiones de seguridad en zonas fronterizas.

En líneas generales se plantea, por un lado, que por las particularidades de la Triple frontera andina se superponen la tradicional agenda deseguridad con una nueva agenda, en donde las llamadas nuevas amenazas cobran relevancia, como es el caso del narcotráfico. Y por otro lado, que los tres Estados han expresado una postura institucional disímil sobre el narcotráfico, que oscila entre el reconocimiento de este como "problema de seguridad", en el caso de Chile, y su incorporación en la agenda de seguridad como tema prioritario, en el caso de Bolivia y Perú.

Desde un abordaje cualitativo con un enfoque descriptivo de tipo 
documental, el presente trabajo se estructura de la siguiente forma. Primero, describe las particularidades del área en estudio con el propósito de situar el problema. Segundo, aborda los contenidos de la agenda de seguridad internacional, enfatizando la idea que en la Triple frontera andina se superpone una agenda tradicional con una nueva agenda, en donde las llamadas nuevas amenazas cobran relevancia, como es el caso del narcotráfico. $Y$ en tercer término, se analiza la situación del narcotráfico, como amenaza a la seguridad, en sus particularidades nacionales y subnacionales.

\section{El escenario: la triple frontera Andina}

Como punto de partida es preciso señalar que durante los últimos años las investigaciones sobre el tema de las fronteras han experimentado un renovado interés, vinculado a la formación de nuevos bloques económicos y a un discurso que propone un mundo sin divisiones, ofreciendo variaciones y complejizaciones (Figallo, 2003). La noción de frontera se trata de un concepto polisémico, al que se recurre con distintas acepciones dentro de las Ciencias Sociales (Bartolomé, 2005), y dinámico que ha variado a lo largo de la historia. Por tanto, la discusión acerca del concepto está en curso y no ha supuesto consensos en torno a una sola definición.
Bonnet (2016) sostiene que es a partir de los procesos emancipatorios vividos en Hispanoamérica, en los inicios del siglo XIX, que las fronteras comenzaron a ser pensadas desde los intereses de los Estados nacionales, no sólo como los derechos sobre las tierras, sino respecto a la importancia de definir sus límites. Así, se formaliza la idea de soberanía y de dominio de los gobernantes sobre los nuevos Estados, sus pobladores y los territorios que los conformaban.

Desde el campo de las Relaciones Internacionales, las fronteras han sido abordadas principalmente en términos militares y geopolíticos lo cual coincide con la tradición teórica realista en la política internacional en la cual la seguridad del Estado está estrechamente vinculada con la guerra. Para García esto se debe a que: “(...) la mayoría de las guerras interestatales han sido por la conquista del territorio, el pensamiento geopolítico ha enfatizado la centralidad de la competencia y la adquisición del territorio en las dinámicas de la política mundial y la función militar de las fronteras. En este sentido, la sobrevivencia del Estado depende del combate contra las incursiones militares de otros Estados (...)" (2015b: 122).

En la actualidad, las transformaciones en la política mundial han demostrado la debilidad de este enfoque para la compresión de las relaciones entre actores en el sistema internacional (García, 2015b) y en rasgos generales, 
el tradicional concepto de frontera político-administrativa, definida por un límite fijo sobre el territorio ha sido rebasado. Medina (2006) puntualiza que hoy presenciamos un derrumbamiento de las fronteras tradicionales y la emergencia de un nuevo paradigma, que el propio Estado- nación ha permitido y proporcionado.

De esta manera, la realidad fronteriza: “(..) se vislumbra desde una perspectiva compleja, internacional y transfronteriza, inserta en diversos procesos de globalización, de reivindicación y reestructuración de las identidades colectivas" (Medina, 2006: 13-14). Coincidiendo con este planteamiento, Tapia (2012) postula que en la actualidad se asiste a un renacimiento del estudio de las fronteras en el contexto de los discursos globalizadores que discuten la pérdida o no de importancia de los límites. Los estudios de las fronteras, por tanto, tenderían a considerar la mirada desde "abajo hacia arriba" por sobre su abordaje tradicional desde "arriba hacia abajo", con lo cual se recogen las experiencias individuales y las formas en que las fronteras impactan en las prácticas diarias de las personas que las habitan.
En América del Sur, señala Bartolomé (2002), la importancia estratégica de los puntos fronterizos no es novedosa. En el caso de la Triple frontera andina, su actual importancia radica en que se la considera zona estratégica, especialmente por los fenómenos de la migración ilegal, el contrabando y el narcotráfico, lo cual es posibilitado entre otras cosas por sus particularidades geográficas, con baja altura y pocos accidentes geográficos, que finalmente permiten la existencia de unos doscientos pasos no habilitados, en los que, incluso, se puede transitar con un vehículo que no tenga tracción en las cuatro ruedas.

La Triple frontera andina que comprende franjas territoriales de la XV región chilena de Arica y Parinacota ${ }^{1}$, del departamento peruano de Tacna y del departamento boliviano de Oruro y Potosí, es un espacio territorial trinacional que tiene un legado de disputas, separaciones y anexiones entre los tres países (RihiSausi \& Coletti, 2010). Si bien esta triple frontera surge en el año 1929, con el Tratado de Lima, después de una larga disputa diplomática que se extendió por cuarenta y cinco años (1884-1929), por la soberanía de las provincias de Tacna y Arica

La Región de Arica Parinacota, cuya capital es Arica, fue creada en enero de 2008, después de la escisión en dos de la antigua Primera Región de Chile (Tarapacá). Vale señalar también que la XV Región de Arica y Parinacota comparte una frontera de 166 kilómetros con Perú y de 782 kilómetros con Bolivia ( Cámara de Diputados, 2013a). 
(González, 2009), sus orígenes se remontan, dependiendo del análisis, al Tratado de Ancón de 1883 o al Uti Possidetis luris de 1810. Por tanto, esta frontera está profundamente relacionada a la Guerra del Pacífico y los 45 años de postguerra, que han generado un imaginario de conflicto en la población de los tres países.

González Miranda (2007), al analizar sus raíces históricas, indica que una de sus características es que está indisolublemente vinculada también a Bolivia ya que por un lado, el puerto de Arica desde la época colonial ha sido la conexión natural de Bolivia con el mundo y en el imaginario boliviano siempre ha sido este puerto al cual se mira para recuperar su cualidad marítima perdida en la Guerra del Pacífico, y por otro lado, la tradicional economía vertical del mundo andino siempre ha vinculado el oriente con el occidente (y no el norte con el sur), por lo tanto, los aymaras del altiplano boliviano consideran que los pisos ecológicos que le llevan hasta la costa forman parte de su economía complementaria y de su cosmogonía.

Su dinámica trinacional es innegable y, además, está muy presente en el imaginario no sólo de las regiones involucradas sino que también en las tres naciones. En este sentido, hay que precisar que si bien esta frontera posee límites bien demarcados, que atienden lo físico y que se expresan en el territorio con la demarcación político-administrativa entre los tres
Estados, estos no necesariamente coinciden con la línea de frontera que se expresa en el espacio.

Lo que se produce entonces es una situación particular, ya que al estar la línea de frontera en la conciencia de sus habitantes, tanto de los que habitan lejos de ella, como de los viven en la frontera misma (González, 2009), el territorio pasa a formar parte estructurante de la memoria individual y colectiva, lo espacial encuentra campos de expansión en la imaginación y en la conciencia de la población (Medina, 2006). De esta manera, esta Triple frontera andina se configura como un Geosímbolo es decir, es un demarcador espacial para estructurar y darle sentido al territorio (Rajchenberg \& Héau-Lambert, 2007).

Como un espacio interestatal condensa las relaciones entre las poblaciones locales y el accionar de los diferentes niveles del Estado. En este sentido, la línea de frontera continúa siendo competencia de los gobiernos nacionales y en el área de frontera, entendida como la región o área en relativa proximidad al límite, donde las dinámicas de cambio y las prácticas cotidianas están afectadas por la misma presencia del límite, las competencias son compartidas entre los gobiernos nacionales $y$ subnacionales (regionales y/o locales).

Los fenómenos que se producen en esta región fronteriza tienen al mismo tiempo una dimensión local 
y regional, configurándose como un espacio interméstico, es decir, un espacio en donde se entrecruzan factores internacionales, regionales e internos que se superponen o interactúan, y que trascienden la tradicional noción de soberanía estatal (Bartolomé, 2006). Para Fuentes (2008) los procesos de globalización se han expresado con mayor fuerza y crudeza en los espacios alejados de los grandes centros urbanos, donde el alcance del Estado parece más débil y precario y la Triple frontera andina no es la excepción.

En esta línea, es posible observar por un lado la presencia de contrabando desde todas las direcciones, destacándose aquel desde Chile hacia Bolivia, al amparo de la Zona Franca de lquique y por otro, que la frontera entre los tres países ha sido utilizada, especialmente a través de pasos no habilitados (Cámara de Diputados, 2013a)², para el contrabando de cocaína, no siendo la región circunvecina a las fronteras productoras de hoja de coca, pero sí una plataforma para la exportación (González, 2007).

Esta región fronteriza presenta una escasa densidad poblacional y baja presencia estatal. Los tres Estados presentan un superpoblamiento alrededor de la zona metropolitana, en donde se encuentran las mejores condiciones climáticas y localización de los centros urbanos e industriales más relevantes, lo que se ha traducido en que se encuentre la presencia de espacios vacíos, principalmente por el desierto. Para Garay (2005:97) los espacios vacíos son "aquellos que teniendo presencia de autoridades, estas actúan de modo lejano, sin contar con núcleos urbanos consolidados, con servicios precarios y ocupación por vía militar, que ejerce control sobre la zona".

En el caso chileno, lo que se produce no es un espacio donde no exista imperio de la ley por dominio de organizaciones no gubernamentales, sino que la presencia del Estado es mediatizada por los factores de acceso, densidad de población y calidad de los servicios. Por tanto, se advierte una baja presencia de la institucionalidad administrativa, pero que no es foco de ingobernabilidad.

Los territorios de los tres países que convergen en la Triple frontera andina constituyen a la vez fronteras internacionales e internas. Como fronteras internacionales las dinámicas socio-económicas en el marco de

El informe de la Comisión especial investigadora acerca de la implementación del denominado "Plan Frontera Norte" consigna que en esta zona existen 140 pasos no habilitados en un área que abarca 1.350 kilómetros. En el límite con Bolivia, hay 106 de estos pasos, en Perú 30 y Argentina 4. 
la globalización han generado una inusitada importancia de esta zona en torno a las variables comercio y exportación de bienes primarios, infraestructura y seguridad; y en su condición de fronteras internas, se caracterizan por su marginalidad y exclusión histórica respecto de los centros de poder nacional (García, 2015b).

En Chile, el concepto de frontera interior fue acuñado a partir de algunas reflexiones y propuestas surgidas al interior del Ejército y fueron calificadas en los rangos: críticas, intermedias y no críticas. Entendiendo por fronteras internas críticas cuando, entre otras, sus condiciones antrópicas, de infraestructura y de servicios se encuentran en desmedro y presentan rasgos naturales extremos, dificultándose la accesibilidad, la habitabilidad, el autosostenimiento, el desarrollo y la integración (Masalleras \& Ortega, 2012). Actualmente en la Región de Arica y Parinacota las comunas de Camarones, Putre y General Lagos son consideradas Zonas Aisladas, lo que implica la consideración de la existencia de fronteras interiores que impiden el acceso óptimo entre las diversas localidades en cuestión (Ministerio de Obras Públicas y Vivienda, 2011).

Esta triple frontera se caracteriza también por tener un alto índice de pobreza. En Chile, tres de las comunas más pobres son fronterizas. En el altiplano en Bolivia y las comunidades de frontera con Chile y Perú en particular, son las áreas de mayor pobreza en el país, con estrechos vínculos con el Alto La Paz. En el Perú, tanto Puno, Tarata como Tacna, han sido siempre zonas de atraso sin ser las más deprimidas del país, pero es la región de mayor presencia indígena aymara (González, 2007).

Por su dinámica trinacional es también un lugar de encuentro de nacionalidades diversas pero con identidades étnicas compartidas, donde coexisten múltiples rutas ancestrales indígenas, principalmente Aymara y Atacameñas, las cuales surcan caminos entre las cordilleras y el altiplano, reincidiendo en itinerarios humanos -migratorios, comerciales y de pastoreo, de larga duración y muchos de ellos de carácter prehispánicos (Valdebenito \& Lube, 2014).

La Triple frontera andina presenta particulares procesos de flujos migratorios y una historia de relaciones comerciales formales e informales. Con respecto a lo primero, el paso terrestre entre la frontera peruana, Santa Rosa, y la frontera chilena, Chacalluta, es el segundo cruce internacional más transitado de Sudamérica (Potestá, 2011) y es la ruta de migración peruana para trasladarse por tierra a otros países sudamericanos, como Argentina $y$ otras regiones chilenas, y también itinerario preferente de la migración de bolivianos que viajan desde la 
capital hacia las regiones chilenas de Tarapacá y Antofagasta (Valdebenito \& Lube, 2014).

Por otra parte, es una de las rutas centrales de comerciantes de las tres nacionalidades, especialmente bolivianos y peruanos ya que la ciudad de Arica se constituye como un fundamental eje articulador entre los países Andinos, debido a su rol de "nodo internacional" con Perú y Bolivia. González Miranda (2007) precisa que un rasgo importante es el bajo peso específico que esta región transfronteriza tiene para los respectivos países, desde un punto de vista macroeconómico. En este sentido, si bien las ciudades limítrofes, desde una perspectiva macroeconómica, excluyendo la minería, tienen una importancia menor respecto de las economías nacionales, estas regiones son claves desde una perspectiva micro-económica y también como plataformas de exportación o reexpedición de productos, sin mencionar su relevancia sociopolítica y su importancia cultural (étnica).

\section{Agenda de seguridad internacional y las nuevas amenazas}

En el escenario Post-Guerra Fría, la comprensión de la seguridad se ha expandido y profundizado hacia objetos y referentes que van más allá de lo militar y lo estatal (Buzan,
1997). Desde el campo de las Relacionales Internacionales, se ha producido una reflexión teórica que ha planteado la necesidad de ampliar la agenda de seguridad de los Estados para incluir temas que la definición tradicional de seguridad, entendida fundamentalmente en términos de amenazas militares externas, no contemplaba.

En este sentido, las investigaciones de Buzan y Waever fueron un intento, por un lado, de ampliar la noción de seguridad, para incorporar en su definición amenazas no convencionales y conflictos que provenían de otro ámbito y por otro, encontrar el nivel de análisis adecuado para entender el sistema internacional Post-Guerra Fría. Bartolomé (2013b) puntualiza que la flexibilización de la matriz westfaliana permitió y promovió la incorporación a los análisis de seguridad internacional de actores no estatales y dinámicas transnacionales que trascienden los límites de un Estado para alcanzar a dos o más unidades políticas de ese tipo.

Desde el enfoque constructivista el sistema internacional no es una realidad dada a los actores, ni que el interés nacional sea un conato estático y prefijado independiente de la interacción de actores. Por el contrario, el sistema internacional es producto de la acción de los actores, donde se generan rasgos de identidad para definir sus intereses y posicionamiento (Orozco, 2006). 
La seguridad es un "acto discursivo" por el cual, sólo después de que un tema es definido como tal por la elite, puede ser considerado de esa manera. Así, la "realidad objetiva" de una amenaza a la seguridad es menos importante que su percepción por parte de los gobiernos y las sociedades (Sampó, 2011). La seguridad como "acto discursivo" lo convierte en un factor de importancia que legitimiza el uso de medidas especiales fuera de proceso político normal.

A dicho fenómeno, Weaver lo denominó securitizar un tema o problema y estudiar el proceso de securitización es estudiar la política de poder de un concepto (Griffiths, 2007). Para Buzan, Weaver y De Wilde los estudios de securitización tienen por objeto "lograr el entendimiento preciso y cada vez mayor de quién es el actor que securitiza, en qué asuntos (amenazas), para quién securitiza (objeto referente), por qué, con qué resultados y no menos importante bajo qué condiciones (es decir, que explica que la securitización es exitosa)" (1998:32). Es decir desde este enfoque, la seguridad es, ante todo, una definición política ya que lo que un actor considera una amenaza a su seguridad y la manera en que define su seguridad depende de las circunstancias, así como de las características de ese actor.

Estos cambios en la esfera de la seguridad internacional corroboran la insuficiencia de aquellos abordajes tradicionales, caracterizados por una percepción estadocéntrica de los actores, el carácter interestatal de sus relaciones, y la preponderancia del poder militar (Sampó, 2011) y plantean la necesidad de una revisión a los múltiples temas que componen hoy la agenda de seguridad internacional, dada la naturaleza trasnacional e interestatal de las actuales amenazas a la seguridad, protagonizadas por actores no estatales. Desde esta perspectiva cobran relevancia las llamadas nuevas amenazas.

Sampó (2011), al referirse a las nuevas amenazas, advierte que en su gran mayoría los fenómenos que suelen englobarse bajo este rótulo no son nuevos, siendo la única excepción la llamada guerra informática. Por esta razón, encontramos en la literatura especializada a autores que optan por otro tipo de denominaciones como amenazas no convencionales o amenazas trasnacionales. Sin embargo, señala Sampó, su novedad radica en la jerarquía que han adquirido dentro de la Seguridad Internacional, como también la forma en la que se manifiestan.

Bartolomé (2013a), al analizar la seguridad internacional en el siglo XXI, indica que las amenazas no convencionales a la seguridad reconocen tres regularidades: sus protagonistas son actores no estatales; no siempre emplean la violencia como herramienta racional de política; y en caso de usar la violencia, lo hacen 
fuera de los formatos tradicionales asociados a la lógica clausewitziana, incursionando en lo que usualmente se conoce como asimetría.

Más allá de estos tres elementos, esta esfera se caracteriza por su heterogeneidad "que se incrementa por diferentes procesos de securitización, dando lugar a una situación que fue simbólicamente definida como "incertidumbre estratégica" o "mundialización del miedo". Es decir, una permanente percepción de inseguridad que alcanza a todos los individuos, sin que puedan evitarlo, en la cual los peligros y amenazas no reconocen una fuente clara ni limitaciones territoriales o políticas a su accionar" (Bartolomé, 2013a:49).

Existe cierto consenso en que las amenazas trasnacionales incluyen siete fenómenos, a saber: flujos migratorios, terrorismo, criminalidad organizada, proliferación de Armamento de Destrucción Masiva, el deterioro ambiental, la guerra informática y la proliferación de armamento pequeño/ liviano (Bartolomé, 2006). Lo particular de estas problemáticas, es que ninguna de ellas puede ser jerarquizada en relación a su importancia, peligrosidad o probabilidad de ocurrencia.

Sampó expone que una de las razones de ello, es que " la valoración de una amenaza depende de la situación específica de cada Estado que, a través de un proceso de esencia constructivista, la securitiza o desecutiriza de acuerdo a las circunstancias" (2011: 88-89). Por otra parte, para Bartolomé (2013a) esto sucede porque los contornos de estos fenómenos son difusos, se utilizan diferentes enfoques para analizarlos, y su gravedad varía de acuerdo a criterios espaciales y temporales.

Dentro del repertorio de amenazas transnacionales presentes en América Latina, se destaca la criminalidad organizada bajo diferentes manifestaciones, las cuales coinciden en parte con lo que Moisés Naím (2003) ha denominado las cinco guerras de la globalización. La Organización de Estados Americanos (2006) ha advertido que la mayoría de los países del continente americano enfrentan un fenómeno de profundo impacto: el crimen organizado, vinculado principalmente al tráfico de drogas, al lavado de activos, al tráfico de armas, a la trata de personas, y a los secuestros, entre otros delitos.

Su importancia y gravedad es tal que en algunos países de la región se han desarrollado zonas consideradas "reductos de impunidad", en los que la presencia del Estado está siendo remplazada por el poder y la influencia de estos grupos criminales. Por tanto, entendiendo la naturaleza del fenómeno, es posible señalar que para enfrentar las nuevas amenazas es necesario reformular el concepto de soberanía, debatir sobre la legitimidad del uso de la fuerza, resaltar la necesaria multidimensionalidad de las 
respuestas y las reformas estructurales y operativas que ello requiere (Sampó, 2011) y por consiguiente, incrementar la cooperación intergubernamental para la comprensión y definición de la amenaza con el objetivo de elaborar estrategias compartidas (Evans, 2008).

\section{Superposición de agendas de seguridad en la triple frontera}

Como postula Bartolomé (2013), los cambios registrados en el plano global dentro del campo de la seguridad internacional han generado una nueva lectura de la situación que, en esta dimensión, atraviesa América Latina. Se advierte una persistencia de temas considerados tradicionales, cuyas raíces llegan a ser incluso decimonónicas, junto a cuestiones de aparición más reciente o valoradas de diferente manera, configurando una dinámica agenda.

En el caso de la Triple frontera andina, parafraseando a Fuentes (2008) se "superponen las agendas de seguridad", lo que implica que se topen las agendas de seguridad de cada uno de los países que componen esta tiple frontera, y que se condensen las tensiones y dinámicas entre la agenda tradicional, caracterizada principalmente por disputas de territorios y/o marítimos, y la nueva agenda de seguridad donde las prioridades son las nuevas amenazas (García, 2015b). Esto ha derivado en que las agendas de seguridad sean amplias, variadas y heterogéneas en los tres países. Para comprender esta situación, el siguiente cuadro resulta útil, puesto que permite comparar cuáles son las principales amenazas percibidas por los tres Estados.

Para su elaboración, se consideran los cinco sectores de análisis propuestos por Buzan en el marco de la Teoría de los Complejos de Seguridad: militar, político, económico, societal y ambiental, las matrices de análisis propuestas por Hernández (2013) en su investigación sobre la seguridad en Bolivia, Chile y Perú desde la Escuela de Copenhague y documentos oficiales de los tres gobiernos.

A partir de la información contenida en el cuadro es posible identificar la perspectiva clásica de la seguridad concebida en términos westfalianos, lo cual se traduce en que para Bolivia y Chile la principal amenaza está concebida en términos militares relacionada con el intento de vulneración a la integridad e independencia del territorio en el primer caso, y con una hipótesis de conflicto con sus vecinos, en el segundo. Esta perspectiva coexiste con una situación mucho más complicada en materia de amenazas no convencionales, protagonizada por actores no estatales y desplegada espacialmente en forma transnacional.

En este sentido, destaca la criminalidad organizada y el terrorismo bajo diversas manifestaciones, las cuales suelen 
Cuadro 1: Percepción de amenaza por sector y país

\begin{tabular}{|c|c|c|c|}
\hline \multirow{2}{*}{ Sector } & \multicolumn{3}{|c|}{ Percepción de amenaza por país } \\
\hline & Bolivia & Chile & Perú \\
\hline Militar & Agresión interestatal & $\begin{array}{l}\text { Hipótesis de conflicto } \\
\text { vecinal. }\end{array}$ & $\begin{array}{l}\text { Grupos terroristas y subversivos. } \\
\text { Delincuencia común organizada y } \\
\text { Tráfico ilícito de drogas. } \\
\text { Corrupción. } \\
\text { Depredación del medio ambiente. }\end{array}$ \\
\hline Político & $\begin{array}{c}\text { Iniciativas autonómicas. } \\
\text { Narcotráfico y pandillas. } \\
\text { Corrupción }\end{array}$ & $\begin{array}{l}\text { Conflicto violento } \\
\text { étnico- social. } \\
\text { Migración }\end{array}$ & $\begin{array}{l}\text { Terrorismo. } \\
\text { Narcotráfico. } \\
\text { Corrupción. }\end{array}$ \\
\hline Económico & $\begin{array}{l}\text { Amplio mercado informal. } \\
\text { Reducido clima de inversión } \\
\text { y competencia. } \\
\text { No hay respeto por la } \\
\text { propiedad privada. } \\
\text { Banca descoordinada del } \\
\text { sistema capital }\end{array}$ & $\begin{array}{l}\text { Concentración de } \\
\text { capital. }\end{array}$ & Economía paralela. \\
\hline Societal & $\begin{array}{l}\text { Incumplimiento de la ley. } \\
\text { Discriminación. } \\
\text { Corrupción. }\end{array}$ & Discriminación. & $\begin{array}{l}\text { Incumplimiento de la Ley. } \\
\text { Discriminación. } \\
\text { Corrupción. }\end{array}$ \\
\hline Ambiental & $\begin{array}{l}\text { Granizada. } \\
\text { Inundaciones. } \\
\text { Sequía. } \\
\text { Sismos. }\end{array}$ & $\begin{array}{c}\text { Sismos. } \\
\text { Sequía. } \\
\text { Tsunami. } \\
\text { Tormenta invernal. } \\
\text { Inundación. }\end{array}$ & $\begin{array}{l}\text { Sequía. } \\
\text { Granizada. } \\
\text { Sismos. } \\
\text { Inundaciones. }\end{array}$ \\
\hline
\end{tabular}

Fuente: Elaboración propia a partir de: Hernández (2013); Gobierno de Bolivia (2008); Gobierno de Chile (2010); Gobierno del Perú (2005).

vincularse de manera directa con la gobernabilidad, lo que para Bartolomé conforma un círculo vicioso, a saber: "caídas acentuadas de los niveles de gobernabilidad pueden erosionar la capacidad estatal para ejercer autoridad sobre espacios geográficos que se tornan así atractivos para el asentamiento de organizaciones vinculadas con la criminalidad y el terrorismo. Inversamente, en la medida en que le es disputado al Estado su control territorial y el monopolio de la violencia, la gobernabilidad se ve negativamente afectada" (2013b:46).

En cuanto a la criminalidad organizada, Perú y Bolivia se encuentran insertos en los esquemas globales de esta amenaza transnacional, siendo las manifestaciones predominantes el narcotráfico, la corrupción y el lavado de dinero. Como se ha indicado en páginas anteriores, estos dos países junto a Colombia elaboran —sin considerar los volúmenes de cannabis 
y heroína - la totalidad de la cocaína que se produce a nivel mundial, lo cual se configura como un negocio muy lucrativo y que se expande por toda la región, utilizando complejas rutas transfronterizas entre Bolivia, Chile y Perú (García et al., 2001).

El lavado de dinero, como consecuencia de la producción de droga, constituye una economía en paralelo. Para Gamarra (2004) lo que sucede es que los negocios ilegales, producto de la comercialización de drogas propicia la expansión de la economía ilegal, la cual se caracteriza por la versatilidad y flexibilidad de su organización, rasgos que le permiten eludir las regulaciones nacionales y los rígidos procedimientos de la colaboración policial internacional. Las organizaciones que se dedican al tráfico de drogas, postula Montañés (2000), se relacionan a través de redes en las que se vinculan todo tipo de negocios, siendo el núcleo del sistema, el blanqueo de dinero, punto en el que la economía ilegal se funde con la formal mediante su introducción en los mercados financieros a través de complejos planes y redes comerciales internacionales.

En este sentido, en algunos países andinos la economía criminal del narcotráfico se ha vuelto parte principal de la economía nacional, en términos de exportaciones, entrada de divisas, importaciones, mejoramiento de la balanza de pagos, reducción del endeudamiento, inversiones, consumos, empleo, producto bruto interno y contribución al crecimiento (Kaplan, 1996). Además, en aquellos países en donde las instituciones públicas son débiles, existe mayor probabilidad que estas sean corrompidas (Niño, 2011), con el propósito de erosionar las capacidades del Estado y aumentar la impunidad de las acciones delictivas. La corrupción concede así la posibilidad de evitar el aparato legislativo comprando inmunidad y/o dirigiendo las agencias de seguridad contra la competencia.

Strange señala que las actividades declaradas criminales e ilegales por el Estado, imitan al mismo tiempo muchas de las características del gobierno formal: "por ejemplo, su autoridad — como la del Estado- es ejercida a través de una estructura de poder establecida, según la cual la obediencias recompensada y la desobediencia es castigada, en ocasiones mediante el uso de la violencia y siempre mediante la amenaza de la violencia (...)" (2001: 161).

En Perú además, una amenaza latente es el terrorismo vinculado a la organización insurgente de Sendero Luminoso que en los últimos años ha sufrido un proceso de transformación organizacional a través del cual abandonaron en forma parcial sus objetivos políticos para conseguir sus metas más asociadas con la obtención del lucro. El Ministerio de Justicia y Derechos Humanos de Perú (2013) ha 
corroborado esta situación señalando que se ha constatado remanentes de Sendero Luminoso asentados en los valles de los ríos Apurímac, Ene y Mantaro (VRAEM) bajo el liderazgo de los hermanos Quise Palomino, que cuentan con una fuerza armada considerable, que subsisten gracias a la actividad del narcotráfico, destacando el hecho de que su capacidad militar les permite proveer también seguridad a los narcotraficantes (Crisis Group, 2008). A mediados de la década pasada, el remanente senderista extendió sus actividades más allá de Perú, robando bancos en Bolivia y vendiendo drogas en barrios de clase baja en Buenos Aires, lo que confirma su transnacionalidad (Bartolomé, 2013a).

En el caso de Chile, el Libro Blanco de la Defensa Nacional del año 2010 incorpora las amenazas no convencionales haciendo una distinción en que estas pertenecen a una categoría más amplia que las amenazas tradicionales, la cual es denominada "problemas de seguridad". En esta categoría se incluyen fenómenos como el terrorismo, el narcotráfico, la proliferación de armas de destrucción masiva, la pobreza, las pandemias y otros que no constituyen amenazas propiamente tales, aunque eventualmente puedan transformarse en ellas (Gobierno de Chile, 2010).

Posteriormente, en el año 2012 la Estrategia Nacional de Seguridad y Defensa 2012-2024 intentó precisar un poco más sobre este tema, asumiendo por un lado como nuevas amenazas en el ámbito internacional al narcotráfico, el terrorismo, el crimen organizado y los ciberataques (Ojeda, 2013), y por otro lado, el desplazamiento desde los conflictos interestatales clásicos a lo intraestatal, a lo cual Chile no está ajeno ya sea por proximidad geográfica, porque involucran a nacionales que se encuentran en zonas de riesgo, o porque gravitan sobre alguno de los intereses nacionales (Gobierno de Chile, 2012) .

Las referencias a los "problemas de seguridad" en la frontera norte chilena evidencian que esta comienza a ser percibida bajo la amenaza no convencional del narcotráfico, identificando que esto se encuentra en relación de la proximidad a dos de los principales centros productores de cocaína a nivel mundial y la oportunidad para la penetración de organizaciones criminales extranjeras en el territorio nacional. Esto se plasma en el establecimiento en el año 2011 de una estrategia de control de fronteras denominada "Plan Frontera Norte" con el objetivo de evitar el ingreso y salida de droga y contrabando del país a través de puertos, sectores costeros no habilitados, complejos fronterizos y pasos no habilitados en las regiones de Arica y Parinacota, Tarapacá y Antofagasta, al norte del país. Esta estrategia representa una manera de concreta de implementación de acciones por parte del Estado chileno con base en un nueva agenda de 
seguridad. Para García (2015) la perspectiva del plan se basa en una consideración de la seguridad a partir de las amenazas irregulares o nuevas, donde se busca evitar el paso de determinados bienes y personas a través de las fronteras. Este modelo de control de fronteras actualmente sigue vigente y fue incorporado en el año 2014 dentro del "Plan Nacional de Seguridad Pública y Prevención de la Violencia y el Delito" y del "Plan Nacional contra el narcotráfico 2014 -2020" del actual gobierno de Michell Bachelet.

\section{El narcotráfico en la triple frontera Andina}

Entendiendo la importancia del narcotráfico como amenaza a la seguridad en Bolivia, Chile y Perú y que este no reconoce limitaciones territoriales, es que la Triple frontera andina se configura en un espacio propicio para la proliferación de actividades delictivas ya que históricamente amplias áreas del territorio presentan una baja presencia estatal. En este sentido, para Méndez (2009) cuando se produce un espacio vacío este suele ser ocupado de inmediato por aquellas fuerzas (lícitas o ilícitas) que tienen presencia activa y objetivos específicos en una región determinada.

Esto es lo que sucede en la zona denominada del Valle del Río Apurímac-Ene en el sur del Perú, en donde la economía cocalera prevalece, y ha sucedido en otras zonas de frontera, en donde la autoridad no es ejercida por los gobiernos y sus representantes legítimos sino por las industrias delictivas que han logrado tomar posesión de la economía, del territorio y aun de la cultura local.

Esta idea es compartida por Camperos (2011) quien advierte de la debilidad del Estado boliviano para sentar presencia $y$ ejercer control fronterizo efectivo en un vasto territorio que colinda con Chile y Perú, se ha transformado en una ventana de oportunidad para que las organizaciones criminales evadan el principio de control territorial, lo que pone en entredicho la práctica de la noción de soberanía. En consecuencia, las organizaciones criminales han desarrollando recursos para ampliar y consolidar el comercio de sustancias controladas en la población fronteriza, adquiriendo altos grados de legitimidad entre la población.

El Ministerio de Justicia y Derechos Humanos del Perú, en su Informe sobre el Crimen Organizado del año 2013, especifica que la producción y comercialización de cocaína ha sido durante los últimos cuarenta años la principal actividad productiva de la criminalidad organizada. En este sentido, sólo se le podría equiparar, por su importancia a lo largo de las últimas décadas, el lavado de activos, que, está mayoritariamente orientado a blanquear los recursos producidos por el tráfico ilícito de drogas. Por su 
parte para Sampó (2011) el tráfico de drogas desde Bolivia hacia el resto de la región como también hacia el hemisferio norte, se ha consolidado como un problema de suma relevancia desde que, a principios del siglo XXI, la agenda de seguridad se posiciona al tope de las preocupaciones del subcontinente.

Bolivia, al ser uno de los principales productores de cocaína, junto con Colombia y Perú, adquiere relevancia a la hora de entender la importancia que tiene esta amenaza para la seguridad regional. Tres son los elementos que considera tener en cuenta para comprender que Bolivia sea uno de los centros de preocupación mundial: la fragilidad del Estado y su consecuente dificultad en lo que hace al control del territorio nacional; la porosidad de las fronteras, incrementada por la debilidad de las instituciones estatales; y la arraigada tradición en lo referente al consumo de la hoja de coca (Sampó, 2013). Sobre este último punto, Camperos (2011) puntualiza que aun cuando el cultivo de hoja de coca es legal, durante el proceso de producción se suceden una serie de prácticas ilegales a las que el marco legal, institucional y coercitivo del Estado suele no prestar atención, debido a la inexistencia de capacidades y sistemas regulatorios efectivos.

Bolivia además es un importante país de tránsito, especialmente de cocaína peruana y colombiana. Las particularidades de sus fronteras, que Sampó caracterizaba como porosas y la incapacidad del Estado de ejercer control en el territorio como en los controles fronterizos que indicaba Camperos (2011), Ilevan a que la droga pase a los cinco países con los que limita, al igual que el contrabando de vehículos en ambos lados de la frontera chileno - boliviana. Resulta interesante para la comprensión del fenómeno del narcotráfico la información contenida en el Acta de la segunda sesión de la Comisión Investigadora Plan Frontera Norte de la Cámara de Diputados en donde se expone que este fenómeno se extiende a otros ámbitos delictuales y no sólo a las acciones de tráfico y distribución. En el año 2011 se detectó en Bolivia el registro de padrón de unos 3 mil vehículos, provenientes de Chile (mayormente desde Iquique y zona central) que habían sido robados por bandas y llevados ese año y en anteriores hacia la frontera de Bolivia con el propósito de ser cambiados por drogas (Cámara de Diputados, 2013).

La particularidad del escenario en que se produce el narcotráfico está definida por el carácter tanto rural como urbano de producción y transporte de sulfato y clorhidrato de cocaína que se extiende matizado a lo largo de la región (Giacoman, 2010). Las organizaciones criminales, con el propósito de legitimar sus acciones delictivas, recurren a acciones tales como inversiones sociales, aportes a eventos públicos, desarrollo de espacios y eventos lúdicos de 
renombre, producción y oferta de bienes públicos que el Estado no entrega a plenitud y aportes a campañas políticas (Camperos, 2011). Estas acciones están vinculadas con uno de los elementos que caracteriza al Crimen Organizado y que para Rojas (2006) es que este busca incidir sobre el Estado para conseguir formas de influencia que permitan un marco de impunidad para desarrollar su acción.

Las actividades del narcotráfico se han generalizado en las diversas cuencas cocaleras de Perú, especialmente en las del Huallaga, Ene, Perené, Apurímac y Aguaytía, Ucayali, considerados los tres grandes bastiones en la región de la selva amazónica. La zona del trapecio amazónico se ha constituido en un lugar estratégico, puesto que su ubicación y extensión territorial facilita el desarrollo de las actividades ilícitas, principalmente de acopio y transporte de droga hacia Colombia y con tal propósito en dicho lugar los narcotraficantes han instalado modernos laboratorios de procesamiento de pasta básica de cocaína, caletas y puestos de acopio de cocaína.

Las vías fluviales y terrestres se han convertido en las principales alternativas para transportar droga hacia el trapecio amazónico, a las ciudades del norte y sur del Perú y hacia Chile (Núñez del Prado, 1999). El Ministerio Público de Chile, en su informe del Observatorio del Narcotráfico, ha identificado que las principales rutas utilizadas para el trasiego de drogas desde Bolivia (provenientes principalmente de las zonas del Chapare y Los Yungas) hacia Chile son Santa Cruz - Oruro - Colchane, que enlazan con cinco rutas generales que se dirigen a Chile y desde Perú hacia Chile son Arequipa - Moquehua Tacna, Los Palos - Las Machas / Caleta Vitor; y Puno - Desaguadero - Bolivia - Argentina - Chile (Ministerio Público de Chile, 2015). En este informe se destaca, además, la importancia que la Zona Altiplánica de Bolivia ocupa en el tráfico de cocaína hacia Chile, lo cual se ha manifestado por una parte, en el desmantelamiento en el año 2013, por parte de las Fuerzas Especiales de Lucha Contra el Narcotráfico peruanas, de lo que la prensa escrita denominó un "narco pueblo" en la zona fronteriza con Chile, dedicado al acopio y fabricación de droga, en la localidad de Iruni, Oruro (La Razón, 2016) y por otra, en el hallazgo el año 2015 de una pista de aterrizaje de aviones medianos para el contrabando de combustible y drogas, en el departamento fronterizo peruano de Oruro con destino a las ciudades fronterizas chilenas (La Razón, 2015).

Una de las complejidades de la Triple frontera andina es que en la Región de Arica y Parinacota existen 140 pasos no habilitados y una gran extensión de territorio que posibilita las actividades ilícitas. La Subsecretaría de Prevención del Delito en su Informe Nacional del año 2015 sobre procedimientos policiales por infracción a la Ley de 
Drogas $\mathrm{N}^{\circ}$ 20.000, consigna que en los delitos asociados al tráfico de drogas y del decomiso de ellas en procedimientos policiales, las tres primeras regiones del norte del Chile (Arica y Parinacota, Tarapacá y Antofagasta) son muy significativas para las estadísticas policiales. En este sentido, durante el segundo trimestre del año 2015, el 88,5 \% de los decomisos de clorhidrato de cocaína se concentraron en estas tres, siendo Arica y Parinacota la región con más alto porcentaje de decomiso (49\%) (Gobierno de Chile, 2015).

Respecto a esta región, la Comisión investigadora acerca de la implementación del "Plan Frontera Norte" estableció en su informe final tres tramos fronterizos críticos (Cámara de Diputados, 2013a):

1. El sector costero con una extensión de 55,55 kilómetros que va de 26 a 2.100 metros sobre el nivel del mar. El tramo comprendido entre el hito uno al cinco es altamente vulnerable, ya que corresponde al lugar donde se sitúa la playa Las Machas, que se caracteriza por el desplazamiento de lanchas rápidas. Además, existen 12 sectores costeros inhabilitados, pero que sirven para el tráfico de drogas. En este sentido, cuando funciona el tren Arica - Tacna, con dos salidas diarias, de acuerdo al Tratado de 1929 solo puede ser controlado en Arica, lo que ocasiona que mucha droga y mercancía sea arrojada hasta 25 kilómetros antes de llegar a la estación.

2. El sector precordillerano desde los hitos 27 a 80, con una extensión de 111,4 kilómetros, presenta una alta vulnerabilidad en el paso Laguna Blanca, frente a Alto Perú. Este tramo es un centro de acopio de droga; por el lado peruano tiene características y carreteras pavimentadas que facilitan el tráfico hacia los poblados de Puno y Ayacucho. Otro paso vulnerable es Ancomarca por Perú, pueblo abandonado que sirve de acopio de droga, con rutas ilegales utilizadas para el tráfico de estupefacientes, contrabando de mercadería y también paso de vehículos robados a la región.

3. El sector cordillerano de una extensión de 168 kilómetros, con una altura de 3.800 metros sobre el nivel del mar, presenta una alta complejidad, especialmente en los 20,5 kilómetros en el sector del tripartito, donde cada 15 días hay una feria internacional con intercambio de mercancía, comercio ilegal y tráfico de drogas.

En rasgos generales, las organizaciones no estatales que llevan adelante las actividadesdetráficoycomercialización de cocaína han surgido a la sombra de los grandes carteles criminales extranjeros. En Perú, coexisten formas estructuradas tradicionales como las bandas y organizaciones criminales más desarrolladas que poseen una estructura de jerarquía estándar, y 
que están dedicadas a la comisión de delitos violentos o al tráfico ilícito de drogas. Existen también grupos pequeños y poco articulados entre sí, que actúan contratados por estructuras extranjeras más poderosas, como son los carteles mexicanos que se ubican en los barrios residenciales de Lima y que detentan un poder económico significativo y controlan los más altos niveles de las organizaciones criminales (Crisis Group, 2008) , relegando a un segundo plano a las organizaciones colombianas, las cuales tienen a su cargo el acopio, traslado y comercialización de la droga (Briseño, 2001).

En Bolivia, el narcotráfico está vinculado a mercados internacionales y controlados casi en su totalidad por carteles extranjeros (Camperos, 2011), los que coexisten también con organizaciones de menor tamaño, compuestos por bolivianos, orientados únicamente al mercado interno, que se articulan y cumplen tareas para los carteles internacionales, entre los que se destacan las organizaciones criminales colombianas (cartel del norte del Valle y las Farc), brasileñas (Primer Comando Capital (PCC) y Comando Vermelho), mexicanas (Zetas y cartel de Sinaloa), peruanas (Sendero Luminoso y MRTA) y rusas (mafia rusa). En Chile, la tendencia mayoritaria sería la de bandas delictuales jerárquicamente estructuradas, que compiten entre sí dentro de espacios geográficos y socioculturales definidos (Schulz \& Zúñiga, 2009).
El Observatorio del Narcotráfico en Chile, estima que estas organizaciones adoptan un perfil más cercano a la pequeña o mediana empresa, contando con un núcleo generalmente vinculado por lazos familiares que adopta las decisiones de mayor trascendencia, se reserva el trato con los proveedores, asigna todo el resto de las tareas en relación a las necesidades con el máximo de flexibilidad, y con todo lo anterior disminuye los costos y el riesgo para la empresa criminal (Ministerio Público de Chile, 2015). Esta idea es compartida por Salas (2014) quien precisa que hasta inicios del año 2014 en las cuatro regiones del norte chileno no han sido detectados carteles dedicados al narcotráfico.

Lo que confirmaría la tesis de las policías de que en Chile la estructura que maneja el tránsito de la droga por esta zona se sustentaría en organizaciones familiares con capacidad limitada para mover grandes volúmenes de droga. La mayoría de los detenidos por narcotráfico en esas regiones corresponden a correos humanos o "burreros", que son sorprendidos al ingresar a territorio chileno por pasos no habilitados con Perú y Bolivia o, en tránsito hacia Calama y hacia los puertos de Arica, Iquique y Antofagasta.

\section{Conclusión}

La revisión documental realizada permite establecer que en la 
Triple frontera andina la principal manifestación de la criminalidad organizada es el narcotráfico y es a partir de este que se potencian directa o indirectamente el contrabando, la corrupción y otros ilícitos.

Por consiguiente, las vulnerabilidades que presenta esta frontera ya no sólo están vinculadas a la persistencia de disputas territoriales de origen decimonónico, sino también por la presencia de amenazas no convencionales, de naturaleza no militar y de alcance transnacional, que se ven posibilitados por la permeabilidad de esta frontera y las limitaciones a su control efectivo.

Dos de los países que componen esta triple frontera se sitúan entre los principales productores de cocaína a nivel mundial y sufren el impacto del narcotráfico, lo que supone un enorme desafío a las capacidades estatales por la porosidad de sus fronteras y la debilidad de las instituciones estatales. Los efectos del narcotráfico no sólo se perciben en los países en cuestión, sino también con los cuales comparten amplias extensiones de frontera, como es el caso de Chile.

Los antecedentes señalados llevan a plantear que en esta triple frontera se superponen la perspectiva clásica de la seguridad entendida en términos westfalianos, la cual se traduce en amenazas concebidas en términos militares, con una perspectiva en donde las amenazas no convencionales o nuevas amenazas, protagonizadas por actores no estatales y desplegadas espacialmente en forma transnacional, cobran relevancia. En esta línea, la incorporación de actores no estatales en el marco de la ampliación en los contenidos de la seguridad internacional develan la pérdida por parte del Estado del doble monopolio de sujeto y objeto de las cuestiones de seguridad.

Desde el enfoque constructivista, la inclusión de un tema determinado dentro de la agenda de seguridad no sólo refleja la existencia de un problema, sino también el ejercicio de una opción política que permite la adopción de medidas y acciones espaciales. En esta perspectiva, Bolivia, Chile y Perú han expresado una postura institucional disímil sobre el narcotráfico como amenaza a la seguridad. Esta postura oscila entre el reconocimiento del narcotráfico desde el año 2010 como "problema de seguridad", en el caso de Chile , vinculado a la proximidad a dos de los principales centros productores de cocaína a nivel mundial y a la oportunidad para la penetración de organizaciones criminales extranjeras en el territorio nacional. $\mathrm{Y}$ al reconocimiento como amenaza no convencional e incorporación en la agenda de seguridad como tema prioritario, por parte de Bolivia y Perú.

Finalmente, este artículo permite establecer que la Triple frontera andina presenta un enorme desafío para los 
tres países que la componen, puesto que al ser un espacio interméstico, los fenómenos que se producen tienen al mismo tiempo una dimensión local y regional, lo que traduce desde el ámbito de la seguridad, en la coexistencia de las agendas de seguridad de cada uno de los tres países en donde se entrecruzan las competencias de los gobiernos nacionales y las compartidas entre los gobiernos nacionales y subnacionales. Esta compleja situación, además, se ve agravada por la constatación de ausencia de una agenda de seguridad en común entre los tres Estados, sin negar el hecho de que existen aspectos transversales determinados por amenazas que se presentan en dos o tres de los Estados analizados.

\section{Referencias}

\section{Fuentes primarias}

Cámara de Diputados (2013a). Comisión Investigadora Plan Frontera Norte de la Cámara de Diputados. Sesión 2da.Valparaíso: Cámara de Diputados de Chile.

Cámara de Diputados (2013b). Informe de la Comisión Especial Investigadora acerca de la Implementación del denominado "Plan Frontera Norte". Valparaíso: Cámara de Diputados de Chile.

Gobierno de Chile (2012). Consulta de S. E. el Presidente de la República,
Sebastián Piñera Echenique, al Honorable Senado de la República sobre la Estrategia Nacional de Seguridad y Defensa. Santiago: Gobierno de Chile.

Gobierno de Chile (2010). Libro de la Defensa Nacional. Santiago: Ministerio de la Defensa Nacional.

Gobierno de Chile (2015). Informe Nacional. Procedimientos policiales por infracción a la Ley de Drogas $N^{\circ}$ 20.000. Santiago de Chile: Subsecretaría de Prevención del Delito. Ministerio del Interior y Seguridad Pública. Segundo semestre.

Gobierno de Bolivia (2008). Constitución Política del Estado Plurinacional de Bolivia. La Paz: Ministerio de la Presidencia.

Gobierno del Perú (2005). Libro Blanco de la Defensa Nacional. Ministerio de Defensa.

Ministerio de Justicia y Derechos Humanos (2013). Diagnóstico Situacional del Crimen en el Perú. Documentos de trabajo No. 03. Lima: Ministerio de Justicia y Derechos Humanos.

Ministerio Público de Chile (2015). Informe 2015. Observatorio del Narcotráfico en Chile. Santiago de Chile: Ministerio Público de Chile.

Ministerio de Obras Públicas y Vivienda (2011). Estudio análisis de accesibilidad territorial - Fronteras interiores. Definición de un Plan de Accesibilidad a las zonas aisladas 
del territorio nacional en el período 2004 -2010. Santiago: MOP.

\section{Prensa}

FELCN ubica "narcopueblo" en frontera con Chile; sus habitantes huyeron. La Razón, Perú, 30 de septiembre de 2013. [Fecha de consulta: 26 de marzo, 2016]. Disponible en: < http://www.la-razon.com/ ciudades/seguridad_ciudadana/ FELCN-narcopueblo-fronteraChile-habitantes_0_1916208412. html. >

Hallan pista de $3 \mathrm{~km}$ para el contrabando de combustibles y droga en Oruro. La Razón, Perú, 8 de agosto de 2015. [Fecha de consulta: 26 de marzo, 2016]. Disponible en: < http://www. la-razon.com/nacional/Hallanpista-contrabando-combustiblesOruro_0_2322367805.html >

\section{Fuentes secundarias}

Bartolomé, M. (2002). La Triple Frontera: Principal foco de inseguridad en el Cono Sur Americano. Military Review, 82 (4), 61-74.

Bartolomé, M. (2004). El Empleo del Instrumento Militar Frente a las "Nuevas Amenazas": ¿Es Extrapolable la Experiencia de la OTAN al Hemisferio Americano? Air\&Space Power Journal [en línea], Tercer Trimestre 2004.
[Fecha de consulta: 15 de Febrero, 2016]. Disponible en: $<$ http://www.airpower.maxwell. af.mil/apjinternational/apjs/2004/3trimes04/bartolome.htm>

Bartolomé, M. (2006). La seguridad internacional en el siglo XXI, más allá de Wesfalia y Clausewitz. Santiago: ANEPE.

Bartolomé, M. (2006). Situación del Crimen Organizado en América Latina. Ágora Internacional, 4 (10), $16-20$.

Bartolomé, M. (2013a). Más allá del Crimen Organizado: La reformulación del concepto de insurgencia y su impacto en el entorno estratégico sudamericano. Austral: Revista Brasieira de Estratégia e Relações Internacionais, 2 (3), 47-74.

Bartolomé, M. (2013b). Una visión de América Latina desde la perspectiva de la agenda de la Seguridad Internacional contemporánea. Relaciones Internacionales, (23), 35-64.

Bartolomé, M. (2005) Antropología de las fronteras en América Latina. Ameriquest, 2 (1), 1-17.

Bonnet, D. (2016). Presentación del dossier "Una mirada histórica, teórica e historiográfica sobre la frontera". Historia Crítica (59), 1318.

Buzan, B. (1997). Rethinking security after Cold War. Cooperation and Conflict, 32 (1), 5-28. 
Buzan, B. Et al. (1998) Security: A New Framework For Analysis. United Kingdom: Lynne Rienner Publishers.

Crisis Group (2008). La droga en América Latina I: perdiendo la lucha. Informe sobre América Latina № 25.

Camperos, J. (2011). El crimen organizado (vinculado al narcotráfico) en Bolivia, En: Niño, C. (Ed.) Crimen organizado y gobernanza en la Región Andina: cooperar o fracasar. Quito: Friedrich Ebert Stiftung, pp. 13-28.

Evans, G. (2008). Criminalidad organizada en el Área de la Triple Frontera (Argentina, Brasil y Paraguay) y su impacto en Chile, Bolivia y Perú. Inteligencia, 1 (5), septiembre 2008, 10-27.

Figallo, B. (2003). Espacios nacionales y espacios regionales. Conflictos y concertaciones en las fronteras chaqueñas de Argentina, Bolivia y Paraguay. Anuario de Estudios Americanos, 60 (1), 183-212.

Fuentes, C. (2008). Fronteras Calientes. Foreign Affairs Latinoamérica, 8 (3), 12-21.

Fuenzalida, C. (2011). Diagnóstico del narcotráfico en Chile, implicancias y sus consecuencias en la seguridad interior de nuestro país. Política y Estrategia, (118), Julio - Diciembre, 225 - 243.

Gamarra, E. (2004). La democracia y las drogas en América latina y el Caribe. En: PNUD. La Democracia en América Latina: Hacia una democracia de ciudadanas y ciudadanos: contribuciones para el debate. Buenos Aires: Alfaguara, pp. 245-258.

Garay, C. (2005) "Estados débiles y espacios vacíos. El caso chileno", en: Contreras, Arturo y Garay, Cristian (ed.). Áreas sin ley, espacios vacíos, estados débiles. Santiago: Mago Editores, pp. 83-114.

García, J. et al. (2001). Lucha contra el narcotráfico en Perú. Una estrategia para el gobierno 2011-2016. Lima: IDEI.

García, V. (2015a). "Territorios fronterizos. Agenda de seguridad y narcotráfico en Chile: el Plan Frontera Norte". Estudios Internacionales, (181), 69-93.

García, V. (2015b). Estado y frontera en el Norte de Chile. Estudios Fronterizos, 16 (31), 117-148.

Gascó, M. (2004). El gobierno de un mundo global: hacia un nuevo orden internacional. Barcelona: Intermón Oxfam Editorial.

Giacoman, D. (2010). Lucha contra el narcotráfico y situación carcelaria en Bolivia. Washington DC: Wola .

González, S. (2007) . "La construcción económica de la triple-frontera boliviana, peruana y chilena. La importancia de la Zona Franca de Iquique", en: Simposio Fronteras en Latinoamérica del CLADHE I - IV JUHE, Montevideo, Uruguay, pp. 1-8. 
González, S. (2009a). El Norte Grande de Chile y sus dos Triple - Fronteras: Andina (Perú, Bolivia y Chile) y Circumpuneña (Bolivia, Argentina y Chile). Cuadernos Interculturales, Viña del Mar, 7 (13), pp. 27-42.

González, S. (2009b).El Norte Grande de Chile: La definición histórica de sus límites, zonas y líneas de fronteras y la importancia de las ciudades como geosímbolos fronterizos. Revista de Historia Social y de las Mentalidades, 13 (2), 1-25.

Griffiths, J. (2007). Evolución de las nociones de seguridad $y$ defensa nacional en el continente americano: Análisis de los casos de EE UU de A. , Perú y Chile. Santiago: Tesis presentada para la obtención del grado de doctor en Estudios Americanos, Universidad de Santiago de Chile.

Hernández, D. (2013). Estudio Comparado de la Seguridad en Bolivia, Chile y Perú: Un análisis desde la Escuela de Copenhague. 2008 -2012. Tesis de Magíster Inédita. Santiago: Universidad de Santiago de Chile.

Kaplan, M. (1996). Economía criminal y lavado de dinero. Boletín Mexicano de Derecho Comparado, (87), 217-241.

Masalleras, M. \& Ortega, R. (2012) Fronteras interiores; una contribución del Ejército vigente. Memorial del Ejército de Chile (488), 135-148.
Medina, E. (2006). Aportaciones para una epistemología de los estudios sobre fronteras internacionales. Estudios Fronterizos, 7 (13), 9-27.

Méndez, M. (2009). El impacto del narcotráfico en el ámbito político. La cadena narco: amenaza para la democracia y la gobernabilidad. En: IDEI. Mapa de del Narcotráfico en el Perú. Lima: Instituto de Estudios Internacionales (IDEI) y Pontificia Universidad Católica del Perú, pp. 43-58.

Montañés, V. (2000). Economía ilegal y narcotráfico en América Latina. Papeles de cuestiones internacionales, (69), 109-115.

Naím, Moisés (2003). The Five Wars of Globalization. Foreign Policy, January-February, 29-37.

Niño, C. (2011). Crimen organizado y gobernanza en la Región Andina: cooperar o fracasar. Quito: Friedrich Ebert Stiftung.

Núñez del Prado, A. (1999). El narcotráfico en el Perú: estrategias conjuntas de las Fuerzas Armadas y la Policía Nacional para su erradicación. Madrid: Centro Superior de Estudios de la Defensa Nacional CEDESEN.

OEA (2006). La seguridad pública en las Américas: retos y oportunidades. Washington, DC: Secretaría General Organización de los Estados Americanos.

Ojeda, C. (2013). Amenazas multidimensionales: una realidad 
Sudamericana. Santiago de Chile: ANEPE.

Orozco, G. (2006). El Aporte de la Escuela de Copenhague a los Estudios de Seguridad. Revista Fuerza Armadas y Sociedad, 20 (1) 141-162.

Podestá, J. (2011). Regiones fronterizas y flujos culturales: La peruanidad en una región chilena. Universum, 1 (26), 123-137.

Rajchenberg, E. \& Héau-Lambert, C. (2007). La frontera en la comunidad imaginada del siglo XIX. Revista Frontera Norte, 19, (38), pp. 37-61.

Rihi-Sausi, J. y Coletti, R. (2010). La integración regional $y$ cooperación transfronteriza en América Latina: experiencias y perspectivas. En: Anuario de la Cooperación Descentralizada 2009. Montevideo: Observatorio de Cooperación Descentralizada UE-AL, pp. 190-114.

Rojas, F. (2006). El crimen organizado internacional: una grave amenaza a la democracia en América Latina y el Caribe: II informe del Secretario General de FLACSO. San José: FLACSO.

Salas, A. (2014). El fenómeno de la droga en el norte de Chile. Una amenaza creciente a la seguridad. Actas del VII Congreso del IRI / I Congreso del CoFEI / II Congreso de la FLAEI. La Plata, pp. 1-17.
Salinero, S. (2015). El crimen organizado en Chile: Una aproximación criminológica al perfil del delincuente a través de un estudio a una muestra no representativa de condenados por delitos de tráfico de estupefacientes. Política Criminal, 10 (19), 25-55.

Sampó, C. (2011). Crisis de gobernabilidad, desafíos a la seguridad regional. Los casos de Bolivia y Ecuador (2000-2005). Alemania: Editorial Académica Española.

Sampó, C. (2011). La crisis de gobernabilidad de Bolivia (20002005), su relación con la debilidad del Estado y la Seguridad Regional. Revista Política y Estrategia (121), 151-174.

Serrano, M. (2005). Crimen transnacional organizado y seguridad internacional: cambio y continuidad. En: Serrano, M. y Berdal, M. (comp.). Crimen transnacional organizado y seguridad internacional. México D.F.: Fondo de Cultura Económica, pp. 27-61.

Schulz, C. \& Zúñiga, L. (2009). ¿Crimen organizado en Chile? Policity Brief Series $N^{\circ} 2$. Global Consortium on Security Transformation.

Strange, S. (2001). La retirada del Estado, La difusión del poder en la economía mundial. Barcelona: Encuentro. 
Tapia, M. (2012). Frontera y migración en el norte de Chile a partir del análisis de los censos de población. Siglos XIX- XXI. Revista de Geografía Norte Grande (53), 177-198.

Valdebenito, F. \& Lube, M. (2014). Las fronteras de la modernidad. El espacio Tacnoariqueño y la nacionalización del Norte Grande chileno (1883-1929). Estudios Ibero-Americanos, 40 (2), juliodiciembre, 277-30. 